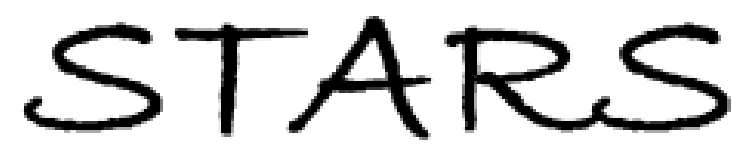

University of Central Florida

STARS

$1-1-2009$

\title{
Excitation wavelength independent sensitized Er3+ concentration in as-deposited and low temperature annealed Si-rich SiO2 films
}

Oleksandr Savchyn

University of Central Florida

Ravi M. Todi

University of Central Florida

Kevin R. Coffey

University of Central Florida

Luis K. Ono

University of Central Florida

Beatriz Roldan Cuenya

University of Central Florida

Find similar works at: https://stars.library.ucf.edu/facultybib2000

University of Central Florida Libraries http://library.ucf.edu

See next page for additional authors

This Article is brought to you for free and open access by the Faculty Bibliography at STARS. It has been accepted for inclusion in Faculty Bibliography 2000s by an authorized administrator of STARS. For more information, please

contactSTARS@ucf.edu.

\section{Recommended Citation}

Savchyn, Oleksandr; Todi, Ravi M.; Coffey, Kevin R.; Ono, Luis K.; Cuenya, Beatriz Roldan; and Kik, Pieter G., "Excitation wavelength independent sensitized Er3+ concentration in as-deposited and low temperature annealed Si-rich SiO2 films" (2009). Faculty Bibliography 2000s. 2095.

https://stars.library.ucf.edu/facultybib2000/2095

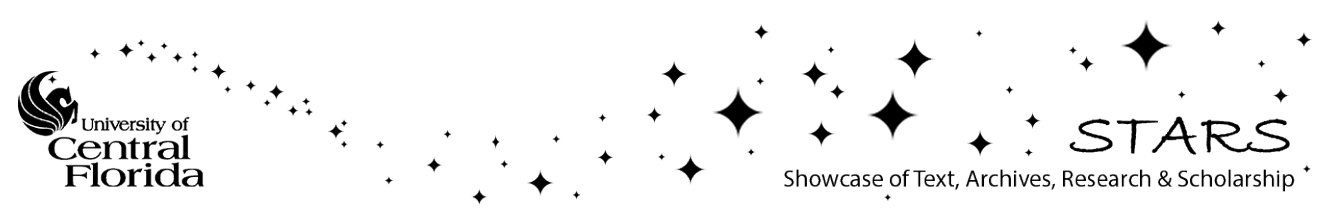


Authors

Oleksandr Savchyn, Ravi M. Todi, Kevin R. Coffey, Luis K. Ono, Beatriz Roldan Cuenya, and Pieter G. Kik 


\section{Excitation wavelength independent sensitized $\mathrm{Er}^{3+}$ concentration in as- deposited and low temperature annealed Si-rich $\mathrm{SiO}_{2}$ films}

Cite as: Appl. Phys. Lett. 95, 231109 (2009); https://doi.org/10.1063/1.3272271

Submitted: 03 July 2009 . Accepted: 16 November 2009. Published Online: 09 December 2009

Oleksandr Savchyn, Ravi M. Todi, Kevin R. Coffey, Luis K. Ono, Beatriz Roldan Cuenya, and Pieter G. Kik

\section{ARTICLES YOU MAY BE INTERESTED IN}

Enhanced thermal stability and nanoparticle-mediated surface patterning: $\mathrm{Pt} / \mathrm{TiO}_{2}(110)$

Applied Physics Letters 94, 083102 (2009); https://doi.org/10.1063/1.3083557

Growth and magnetic properties of ultrathin Fe on Pd(110)

Journal of Vacuum Science \& Technology A 19, 1182 (2001); https://doi.org/10.1116/1.1345912

\section{Applied Physics Letters}

Mid-IR and THz frequency combs special collection

\section{Read Now!}




\title{
Excitation wavelength independent sensitized $\mathrm{Er}^{3+}$ concentration in as-deposited and low temperature annealed Si-rich $\mathrm{SiO}_{2}$ films
}

\author{
Oleksandr Savchyn, ${ }^{1, a)}$ Ravi M. Todi, ${ }^{2}$ Kevin R. Coffey, ${ }^{2,3}$ Luis K. Ono, ${ }^{3}$ \\ Beatriz Roldan Cuenya, ${ }^{3}$ and Pieter G. Kik ${ }^{1,3}$ \\ ${ }^{1}$ CREOL, The College of Optics and Photonics, University of Central Florida, Orlando, \\ Florida 32816, USA \\ ${ }^{2}$ Advanced Materials Processing and Analysis Center (AMPAC), University of Central Florida, Orlando, \\ Florida 32816, USA \\ ${ }^{3}$ Department of Physics, University of Central Florida, Orlando, Florida 32816, USA
}

(Received 3 July 2009; accepted 16 November 2009; published online 9 December 2009)

\begin{abstract}
Erbium sensitization is observed in as-deposited $\mathrm{Er}^{3+}$ doped $\mathrm{Si}$-rich $\mathrm{SiO}_{2}$, ruling out the involvement of $\mathrm{Si}$ nanocrystals in the $\mathrm{Er}^{3+}$ excitation in these samples. The $\mathrm{Er}^{3+}$ excitation cross section in this material is similar within a factor 3 to that of samples annealed at $600{ }^{\circ} \mathrm{C}$ under 355 and $532 \mathrm{~nm}$ excitation. The density of sensitized $\mathrm{Er}^{3+}$ ions is shown to be excitation wavelength independent, while the shape of the $\mathrm{Er}^{3+}$ excitation spectra is governed by a wavelength dependent $\mathrm{Er}^{3+}$ excitation cross section. These findings enable the use of a broad range of wavelengths for the efficient excitation of this gain medium. (c) 2009 American Institute of Physics.
\end{abstract}

[doi:10.1063/1.3272271]

Among the different approaches to the realization of a Si-compatible laser ${ }^{1-5}$ using the emission from silicon sensitized $\mathrm{Er}^{3+}$ in $\mathrm{Si}$-rich $\mathrm{SiO}_{2}$ (SRSO) has received significant attention. ${ }^{6}$ Recently it was shown that luminescence centers (LCs), not Si nanocrystals (NCs), are the dominant $\mathrm{Er}^{3+}$ sensitizer in SRSO. ${ }^{7,8}$ The ability to sensitize $\mathrm{Er}^{3+}$ without $\mathrm{Si}$ NCs has a number of advantages: a higher density of sensitized (indirectly excitable) $\mathrm{Er}^{3+}$ ions, ${ }^{7}$ a favorable temperature dependence of the $\mathrm{Er}^{3+}$ emission, ${ }^{9}$ and a possible reduction in confined carrier absorption ${ }^{10,11}$ and scattering. ${ }^{12}$ While the sensitization of $\mathrm{Er}^{3+}$ by $\mathrm{LC}$ is highly excitation wavelength $\left(\lambda_{\text {exc }}\right)$ dependent, ${ }^{7}$ it is not clear if this is due to a wavelength dependent concentration of sensitizers (and thus sensitized $\mathrm{Er}^{3+}$ ions) or due to a wavelength dependent cross section of the sensitizers. The former would correspond to excitation via an inhomogeneous distribution of LC related levels in the SRSO bandgap leading to a wavelength dependent number of possible transitions, while the latter would correspond to excitation through LCs with an intrinsic wavelength dependent absorption cross section associated with a broad absorption band of each LC. In the present study we demonstrate that the density of sensitized $\mathrm{Er}^{3+}$ ions is remarkably constant with changing $\lambda_{\text {exc }}$ while the $\mathrm{Er}^{3+}$ excitation cross section shows a significant wavelength dependence.

An Er-doped Si-rich $\mathrm{SiO}_{2}$ film (thickness $110 \mathrm{~nm}$ ) containing 12 at. \% of excess Si and 0.63 at. \% of Er was sputter deposited onto a Si wafer (sample temperature $<40{ }^{\circ} \mathrm{C}$ ). An as-deposited sample and two samples, respectively annealed at 600 and $1100{ }^{\circ} \mathrm{C}$ (labeled LTA and HTA for low and high temperature anneal) for $100 \mathrm{~s}$ in flowing $\mathrm{N}_{2}$ and subsequently passivated for $30 \mathrm{~min}$. in forming gas $\left(\mathrm{N}_{2}: \mathrm{H}_{2}\right.$ $=95 \%: 5 \%$ ) at $500{ }^{\circ} \mathrm{C}$ were studied. X-ray photoelectron spectroscopy (XPS) measurements were performed on samples etched to a thickness of $50 \pm 8 \mathrm{~nm}$ using the $\mathrm{Al} \mathrm{K} \alpha$ line $(1486.6 \mathrm{eV})$ of an $\mathrm{x}$-ray source. Photoluminescence (PL)



spectra (resolution $\sim 10 \mathrm{~nm}$ ) were taken at room temperature using the $351 \mathrm{~nm}$ line of a $\mathrm{Kr}$-ion laser $\left(2.7 \mathrm{~W} / \mathrm{cm}^{2}\right)$. Excitation spectra were taken using Xe-lamp emission filtered through a monochromator, using standard lock-in techniques. Time dependent PL measurements (resolution $80 \mathrm{~ns}$ ) were done under pulsed excitation using the 355 and $532 \mathrm{~nm}$ lines of a Nd-doped yttrium aluminum garnet laser (pulse length $5 \mathrm{~ns}$ ). The laser spot area was determined with an accuracy better than $\pm 10 \%$. All spectral PL measurements were done in the linear regime of PL versus power and corrected for system response. The absence of pump induced sample damage was verified for the highest pump power used. More information on the experimental techniques can be found in Refs. 7 and 13.

Figure 1 shows the PL spectra of the as-deposited, LTA and HTA samples taken under continuous wave (cw) excitation at $351 \mathrm{~nm}$. The spectra of as-deposited and LTA samples contain emission bands peaking at $\sim 550,981$, and $1535 \mathrm{~nm}$ corresponding to emission from Si-excess-related $\mathrm{LCs}^{14}$ and $\mathrm{Er}^{3+}$ transitions ${ }^{4} \mathrm{I}_{11 / 2} \rightarrow{ }^{4} \mathrm{I}_{15 / 2}$ and ${ }^{4} \mathrm{I}_{13 / 2} \rightarrow{ }^{4} \mathrm{I}_{15 / 2}$, respectively. The spectrum of the HTA sample exhibits emission bands peaking at $\sim 780$ and $1535 \mathrm{~nm}$ corresponding to emission from Si NCs and the $\mathrm{Er}^{3+}$ transition ${ }^{4} \mathrm{I}_{13 / 2} \rightarrow{ }^{4} \mathrm{I}_{15 / 2}$, respec-



FIG. 1. (Color online) PL spectra of Er-doped SRSO of as-deposited, LTA, and HTA samples under $\mathrm{cw}$ excitation at $351 \mathrm{~nm}$. 


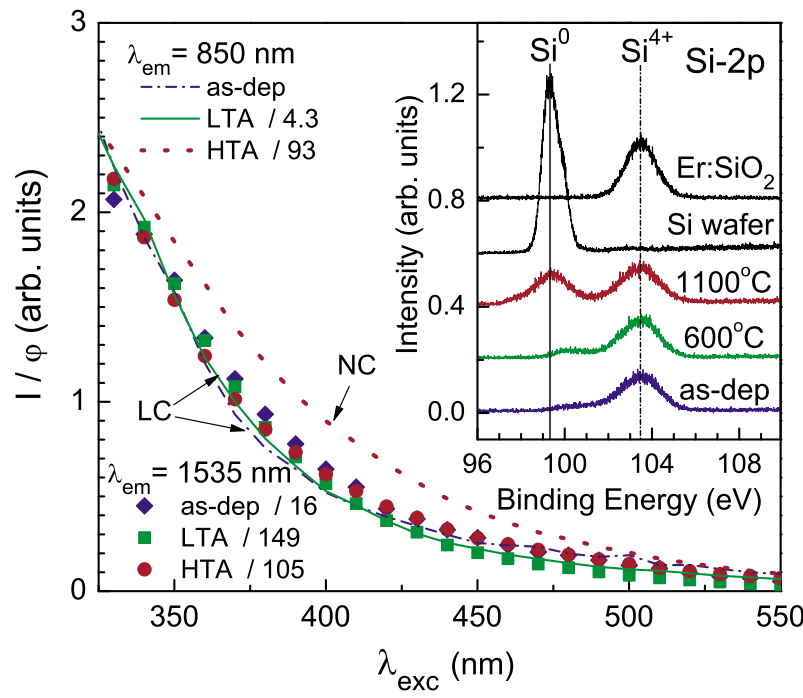

FIG. 2. (Color online) Excitation spectra of the $\mathrm{Er}^{3+}$ emission at $1535 \mathrm{~nm}$ (as-deposited, LTA, and HTA samples), the LC emission at $850 \mathrm{~nm}$ (as deposited and LTA samples), and the Si NCs emission at $850 \mathrm{~nm}$ (HTA sample). The corresponding scaling factors are included. Inset: XPS spectra of as-deposited and annealed (600 and $\left.1100^{\circ} \mathrm{C}\right)$ Er-doped SRSO, a Si (100) substrate, and a sputtered $\mathrm{Er}: \mathrm{SiO}_{2}$ film.

tively. No $\mathrm{Er}^{3+}$ emission was observed in the sample containing a similar Er concentration but no silicon excess under $\mathrm{cw}$ and pulsed excitation.

The inset of Fig. 2 shows XPS spectra from the Si- $2 p$ core level region of Er-doped SRSO films for an asdeposited sample and samples annealed at 600 and $1100{ }^{\circ} \mathrm{C}$ as well as reference data from a Si (100) substrate and a cosputtered unannealed Er-doped $\mathrm{SiO}_{2}$ film. The known binding energies (BEs) of $\mathrm{Si}^{0}$ and $\mathrm{Si}^{4+}$ are indicated by the vertical lines. The XPS spectrum of the as-deposited film shows a clear $\mathrm{Si}^{4+}$ peak, as well as a small broad shoulder in the $\mathrm{BE}$ region where $\mathrm{Si}^{3+}, \mathrm{Si}^{2+}$, and $\mathrm{Si}^{+}$species are expected $(\sim 100-102 \mathrm{eV}) .^{15}$ The latter is attributed to the presence of excess $\mathrm{Si}$ in the film. In the sample annealed at $600{ }^{\circ} \mathrm{C}$ no $\mathrm{Si}^{0}$ signal is observed. The sample annealed at $1100{ }^{\circ} \mathrm{C}$ does exhibit a clear $\mathrm{Si}^{0}$ peak, indicative of the nucleation and growth of extended Si inclusions. These results conclusively show that no extended $\mathrm{Si}$ aggregates are present in the asdeposited sample and the sample annealed at $600{ }^{\circ} \mathrm{C}$.

Figure 2 shows the $\mathrm{cw}$ excitation spectra corrected for photon fluence $\left[\mathrm{I}\left(\lambda_{\text {exc }}\right) / \varphi\left(\lambda_{\text {exc }}\right)\right.$, with I the PL intensity and $\varphi$ $\left(\mathrm{m}^{-2}\right)$ the pump photon fluence per chop cycle] of the $\mathrm{Er}^{3+}$ PL at $1535 \mathrm{~nm}$ in as-deposited, LTA and HTA samples, the LC PL at $850 \mathrm{~nm}$ in the as-deposited and LTA samples and the Si NC PL at $850 \mathrm{~nm}$ in the HTA sample. The $1535 \mathrm{~nm}$ excitation spectra show a gradual increase in the PL intensity for decreasing $\lambda_{\text {exc }}$. The absence of resonances in the $\mathrm{Er}^{3+}$ excitation spectra and their identical behavior confirms that the excitation of $\mathrm{Er}^{3+}$ is predominantly indirect and of the same origin in all samples. Furthermore, the similarity between the $1535 \mathrm{~nm} \mathrm{Er}^{3+}$ excitation spectra and the $850 \mathrm{~nm}$ LC PL of the as-deposited and LTA samples strongly suggests that the sensitization is mediated by the LCs, as was previously proposed. ${ }^{7,8}$ Finally, the significantly different spectral shape of the Si NC excitation spectrum of the HTA sample demonstrates that $\mathrm{Si}$ NCs are not the dominant source of $\mathrm{Er}^{3+}$ excitation in HTA samples.

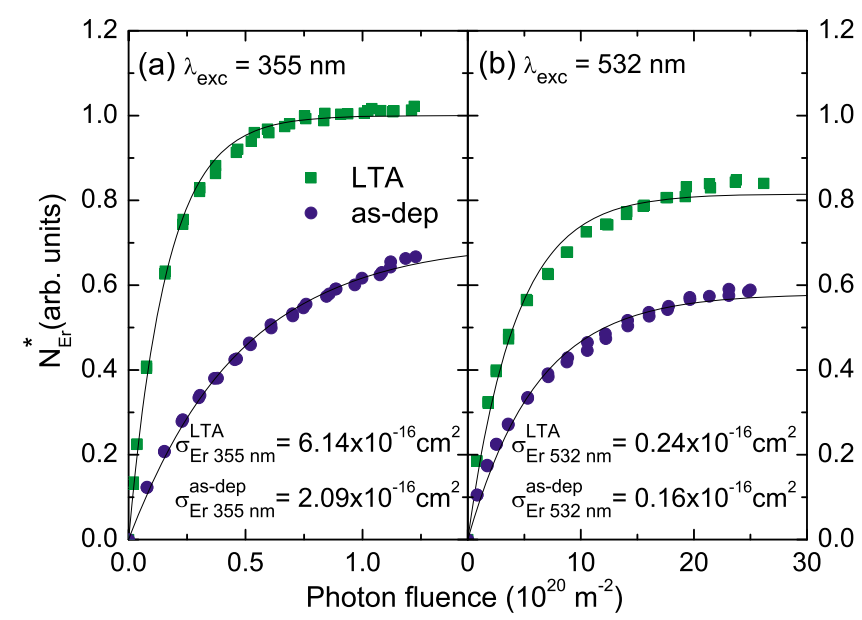

FIG. 3. (Color online) The dependence of the relative density of excited $\mathrm{Er}^{3+}$ ions $N_{\mathrm{Er}}^{*}$ in LTA (squares) and as-deposited (circles) Er-doped SRSO on pump flux under (a) $355 \mathrm{~nm}$ and (b) $532 \mathrm{~nm}$ pulsed excitation. The solid lines represent fits to the data.

Figure 3 shows the $1535 \mathrm{~nm} \mathrm{Er}^{3+} \mathrm{PL}$ intensity at $t=80 \mathrm{~ns}$ after the pulse as a function of pump photon fluence per pulse $\varphi\left(\mathrm{m}^{-2}\right)$ under 355 and $532 \mathrm{~nm}$ excitation for the as-deposited and LTA samples, shown on the same relative scale. No significant $\mathrm{Er}^{3+}$ relaxation at $1535 \mathrm{~nm}$ could be detected on a time scale shorter than $\sim 80 \mathrm{~ns}$, and consequently the signal recorded at $t=80 \mathrm{~ns}$ is considered to be representative of the $\mathrm{Er}^{3+} \mathrm{PL}$ intensity immediately after the excitation pulse. Data on the HTA sample are not included due to the presence of a fast background signal at $1535 \mathrm{~nm}$ unrelated to $\mathrm{Er}^{3+}$. This fast background was also observed in previous work by independent authors. ${ }^{16,17}$ While the exact origin of the background is not known, its presence only in HTA samples suggests that this component is related to transitions in the Si NC or at the Si NC surface. Figure 3 shows an increase and subsequent saturation of the $\mathrm{Er}^{3+} \mathrm{PL}$ at $1535 \mathrm{~nm}$ with increasing photon flux. Assuming that no significant $\mathrm{Er}^{3+}$ relaxation takes place during the excitation, that the LC-mediated $\mathrm{Er}^{3+}$ excitation efficiency is pump fluence independent, and that the $\mathrm{Er}^{3+}$ radiative rate is identical in both samples, the $\mathrm{Er}^{3+} \mathrm{PL}$ intensity immediately after pulsed excitation is given by

$$
\mathrm{I}_{\mathrm{Er}}(\varphi) \propto N_{\mathrm{Er}}^{*}=N_{\mathrm{Er}}\left(1-e^{-\sigma_{\mathrm{Er}} \varphi}\right),
$$

with $N_{\mathrm{Er}}^{*}$ the density of excited $\mathrm{Er}^{3+}$ ions, $N_{\mathrm{Er}}$ the density of sensitized (indirectly excitable) $\mathrm{Er}^{3+}$ ions, and $\sigma_{\mathrm{Er}}$ the total effective $\mathrm{Er}^{3+}$ excitation cross section. Note that due to the multilevel nature of the $\mathrm{Er}^{3+}$ excitation ${ }^{13,18}$ the value of $\sigma_{\mathrm{Er}}$ contains contributions from the excitation cross sections of all sensitized $\mathrm{Er}^{3+}$ levels due to the fact that the observed saturation results from ground state depletion. The solid lines in Fig. 3 represent fits to the measured data using Eq. (1), and show good agreement for both $\lambda_{\text {exc }}$ and for both the samples.

Table I lists the obtained values of $\sigma_{\mathrm{Er}}$ and $N_{\mathrm{Er}}$ based on the fits in Fig. 3. The value of $\sigma_{\mathrm{Er}}$ at $355 \mathrm{~nm}$ in the LTA sample is in agreement with that found previously from $\mathrm{cw}$ measurements. ${ }^{8}$ For both 355 and $532 \mathrm{~nm}$ excitation the difference in $\mathrm{Er}^{3+}$ excitation cross section between the asdeposited and the LTA sample is found to be less than a factor $\sim 3$. The fact that similar values of the $\sigma_{\mathrm{Er}}$ are observed in as-deposited, LTA and HTA $^{7,8}$ samples, combined 
TABLE I. Values of $\sigma_{\mathrm{Er}}$ and $N_{\mathrm{Er}}$ under pulsed 355 and $532 \mathrm{~nm}$ excitation for as-deposited and LTA samples.

\begin{tabular}{lcc}
\hline \hline Parameter|Sample & As deposited & LTA \\
\hline$\sigma_{\mathrm{Er}}(355 \mathrm{~nm}),\left(10^{-16} \mathrm{~cm}^{2}\right)$ & $2.09 \pm 0.22$ & $6.14 \pm 0.63$ \\
$N_{\mathrm{Er}}(355 \mathrm{~nm}),($ arb. units $)$ & $0.70 \pm 0.07$ & $1.00 \pm 0.10$ \\
$\sigma_{\mathrm{Er}}(532 \mathrm{~nm}),\left(10^{-16} \mathrm{~cm}^{2}\right)$ & $0.164 \pm 0.018$ & $0.237 \pm 0.025$ \\
$N_{\mathrm{Er}}(532 \mathrm{~nm}),($ arb. units $)$ & $0.58 \pm 0.07$ & $0.82 \pm 0.09$ \\
\hline \hline
\end{tabular}

with the similar $\mathrm{Er}^{3+}$ excitation spectra in these samples (Fig. 2) provides further evidence that the indirect excitation of $\mathrm{Er}^{3+}$ in as-deposited SRSO is the same as in LTA sample and the sample containing Si NCs (HTA).

While the fits in Fig. 3 do not provide absolute values for $N_{\mathrm{Er}}$, the relative magnitudes of $N_{\mathrm{Er}}$ can be compared. We find that $N_{\mathrm{Er}}^{\mathrm{LTA}} / N_{\mathrm{Er}}^{\mathrm{as}-\mathrm{dep}} \approx 1.4$ for both 355 and $532 \mathrm{~nm}$ excitation. Apparently the $600{ }^{\circ} \mathrm{C}$ anneal of the LTA sample only slightly increases the density of sensitized $\mathrm{Er}^{3+}$ ions. This in turn suggests that the density of Si-excess-related sensitizers present in as-deposited samples is not strongly affected by a low-temperature anneal.

Using the values in Table I the origin of the wavelength dependent excitation spectra in Fig. 2 can be determined. At low power, the excitation spectrum is given by

$$
\mathrm{I}_{\mathrm{Er}}\left(\lambda_{\text {exc }}\right) / \varphi\left(\lambda_{\text {exc }}\right) \propto \sigma_{\text {Er }}\left(\lambda_{\text {exc }}\right) \times N_{\text {Er }}\left(\lambda_{\text {exc }}\right) .
$$

Note that this relation leaves open the possibility of a wavelength dependent number of sensitized $\mathrm{Er}^{3+}$ ions. Figure 2 shows that $\mathrm{I}_{\mathrm{Er}}\left(\lambda_{\text {exc }}\right) / \varphi\left(\lambda_{\text {exc }}\right)$ increases by a factor $\sim 20$ and $\sim 32$ for as-deposited and LTA samples, respectively, as $\lambda_{\text {exc }}$ decreases from 532 to $355 \mathrm{~nm}$. By comparison, in this same wavelength range the term $\sigma_{\mathrm{Er}}\left(\lambda_{\text {exc }}\right) \times N_{\mathrm{Er}}\left(\lambda_{\text {exc }}\right)$ obtained from pulsed measurements increases by a factor $\sim 15$ and $\sim 32$ for the as deposited and LTA sample, respectively. The good correspondence between these sets of values indicates that we may directly compare the $\mathrm{cw}$ excitation spectra in Fig. 2 with the values in Table I obtained under pulsed excitation. We find that $N_{\mathrm{Er}}$ is approximately independent of $\lambda_{\mathrm{exc}}$ (Table I). It is therefore concluded that the rapid increase in $\mathrm{Er}^{3+}$ PL with decreasing $\lambda_{\text {exc }}$ is due predominantly to an increase in $\sigma_{\mathrm{Er}}$ and thus of the LC absorption cross section, assuming a fixed number of LCs per $\mathrm{Er}^{3+}$ ion.

The fact that the density of sensitized $\mathrm{Er}^{3+}$ ions does not change with $\lambda_{\text {exc }}$ rules out the possibility that the shape of the $\mathrm{LC}$ excitation spectrum is related to a varying density of LC levels in the SRSO gap. Instead, we must conclude that the LCs exhibit an increasing optical cross section as the excitation wavelength is decreased and exhibit a broad absorption band that extends at least from $2.3 \mathrm{eV}(532 \mathrm{~nm})$ to $3.5 \mathrm{eV}$ $(355 \mathrm{~nm})$. The fact that all LCs exhibit a similar absorption spectrum while a broad PL spectrum is observed seems to suggest that significant relaxation of the LCs can occur after excitation, leading to homogenous broadening. The absence of resonant features in the LC PL spectra around $\mathrm{Er}^{3+}$ transitions seems to indicate that the $\mathrm{LC}$ mediated $\mathrm{Er}^{3+}$ excitation is nonresonant, however further research is needed to determine the details of the energy transfer mechanism.

In summary, indirect excitation of $\mathrm{Er}^{3+}$ in as-deposited Si-rich $\mathrm{SiO}_{2}$ has been demonstrated. The observation of similar values of the $\mathrm{Er}^{3+}$ sensitized cross section and similar excitation spectra in as-deposited samples and samples annealed at 600 and $1100{ }^{\circ} \mathrm{C}$ shows that the excitation mechanism is largely independent of annealing treatment. The increase in the $\mathrm{Er}^{3+}$ emission intensity at $1535 \mathrm{~nm}$ with decreasing excitation wavelength is demonstrated to be predominantly due to an increase in the $\mathrm{Er}^{3+}$ excitation cross section rather than due to an increase in the density of sensitized $\mathrm{Er}^{3+}$ ions. The demonstrated excitation wavelength independent density of indirectly excited $\mathrm{Er}^{3+}$ ions implies that similar gain could be achieved in amplifiers and lasers based on this material using a broad range of pump wavelengths.

This work was supported by the National Science Foundation CAREER No. ECCS-0644228.

${ }^{1}$ T. J. Kippenberg, J. Kalkman, A. Polman, and K. J. Vahala, Phys. Rev. A 74, 051802 (2006).

${ }^{2}$ M. Lipson, J. Lightwave Technol. 23, 4222 (2005).

${ }^{3}$ M. Makarova, V. Sih, J. Warga, R. Li, L. Dal Negro, and J. Vuckovic, Appl. Phys. Lett. 92, 161107 (2008).

${ }^{4}$ Q. Lin, T. J. Johnson, R. Perahia, C. P. Michael, and O. J. Painter, Opt. Express 16, 10596 (2008).

${ }^{5}$ L. Dal Negro, R. Li, J. Warga, and S. N. Basu, Appl. Phys. Lett. 92, 181105 (2008).

${ }^{6}$ M. Fujii, M. Yoshida, Y. Kanzawa, S. Hayashi, and K. Yamamoto, Appl. Phys. Lett. 71, 1198 (1997).

${ }^{7}$ O. Savchyn, F. R. Ruhge, P. G. Kik, R. M. Todi, K. R. Coffey, H. Nukala, and H. Heinrich, Phys. Rev. B 76, 195419 (2007).

${ }^{8}$ O. Savchyn, P. G. Kik, R. M. Todi, and K. R. Coffey, Phys. Rev. B 77, 205438 (2008).

${ }^{9}$ F. Lenz, A. Hryciw, R. DeCorby, and A. Meldrum, Appl. Phys. Lett. 95, 091909 (2009).

${ }^{10}$ D. Navarro-Urrios, A. Pitanti, N. Daldosso, F. Gourbilleau, R. Rizk, G. Pucker, and L. Pavesi, Appl. Phys. Lett. 92, 051101 (2008).

${ }^{11}$ R. D. Kekatpure and M. L. Brongersma, Nano Lett. 8, 3787 (2008).

${ }^{12}$ R. D. Kekatpure and M. L. Brongersma, Phys. Rev. A 78, 023829 (2008).

${ }^{13}$ O. Savchyn, R. M. Todi, K. R. Coffey, and P. G. Kik, Appl. Phys. Lett. 93, 233120 (2008).

${ }^{14}$ M. Y. Valakh, V. A. Yukhimchuk, V. Y. Bratus, A. A. Konchits, P. L. F. Hemment, and T. Komoda, J. Appl. Phys. 85, 168 (1999).

${ }^{15}$ N. Koshizaki, H. Umehara, and T. Oyama, Thin Solid Films 325, 130 (1998).

${ }^{16}$ A. Al Choueiry, A. M. Jurdyc, B. Jacquier, F. Gourbilleau, and R. Rizk, J. Appl. Phys. 106, 053107 (2009).

${ }^{17}$ D. Navarro-Urrios, A. Pitanti, N. Daldosso, F. Gourbilleau, R. Rizk, B Garrido, and L. Pavesi, Phys. Rev. B 79, 193312 (2009).

${ }^{18}$ O. Savchyn, R. M. Todi, K. R. Coffey, and P. G. Kik, Appl. Phys. Lett. 94, 241115 (2009). 